\title{
Immunohistochemical study on antigen-presenting cells in healthy and carious human teeth
}

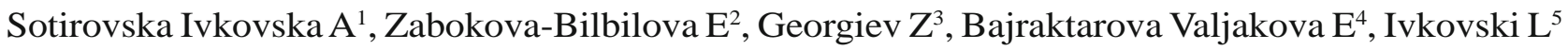 \\ Department of Pediatric and Preventive Dentistry, Faculty of Dentistry, "Ss. Cyril and Methodius” University, \\ Skopje, Macedonia. anasotirovska@yahoo.com
}

\section{ABSTRACT}

Class II major histocompatibility complex (MHC) antigen-presenting cells are associated with the early phase of the immune response.

We have studied the distribution of class II-expressing cells in developing, healthy and carious human teeth to clarify, when human pulp acquires an immunologic defense potential and how this reacts to dental caries. Antigen-expressing cells were identified immunohistochemically with the following monoclonal antibodies: HLADR - for dendritic cells and CD68 - for macrophages.

In the pulp of unerupted developing teeth, HLA-DR-positive cells were distributed mainly in and around the odontoblast layer. A few CD68 positive cells were located more coronary around the blood vessels. In erupted teeth, HLA-DR-positive cells were located, for the most part, just beneath the odontoblast layer. CD68 positive cells were also located coronary, mainly around the blood vessels. Superficial caries lesions caused an aggregation of HLA-DR-positive cells and macrophages in the dental pulp corresponding to the lesion.

These findings showed that: (1) human teeth are already equipped with an immunological defense potential prior to eruption; (2) in the initial stage of caries infection, an immuno-response mediated by class-II-expressing cells is initiated in human dental pulp (Fig. 8, Ref. 33). Text in PDF www.elis.sk.

KEY WORDS: human dental pulp, developing tooth, dental caries, dendritic cells, macrophages, immunohistochemistry.

\section{Introduction}

Various types of immunocompetent cells are present in normal dental pulp (1, 2, 3, 4, 5, 6). Antigen-presenting cells are considered essential for the induction and expansion of the immune reaction, because their interaction with antigen is the first step in immune induction. One of their essential characteristics is to express MHC class II antigen in the lymphoid tissue. They can absorb and process complex antigens and present them to T lymphocytes, a function essential to the initiation of immune responses (7).

The hard-tissue encasement provides a unique pathway of antigenic entry, since the permeability of dentin seems to be critical in determining the quantity of incoming antigens and subsequently the magnitude of the reactions operational in the underlying pulp. There is some evidence showing that pulpal dendritic cells are actually able to respond to trans-dentinal antigen provocation, and

${ }^{1}$ Department of Pediatric and Preventive Dentistry, Faculty of Dentistry, "Ss. Cyril and Methodius" University, Skopje, Macedonia, ${ }^{2}$ Department of Pediatric and Preventive Dentistry, Faculty of Dentistry, "Ss. Cyril and Methodius” University, Skopje, Macedonia, ${ }^{3}$ Department of Pediatric and Preventive Dentistry, Faculty of Dentistry, "Ss. Cyril and Methodius” University, Skopje, Macedonia, ${ }^{4}$ Department of Prosthodontics, Faculty of Dentistry, “Ss. Cyril and Methodius” University, Skopje, Macedonia, and ${ }^{5}$ Histolab, Diagnostic Laboratory for Histopathology and Clinical Cytology, Skopje, Macedonia

Address for correspondence: A. Sotirovska Ivkovska, MD, Department of Pediatric and Preventive Dentistry, Faculty of Dentistry "Ss. Cyril and Methodius” University, Mother Teresa 17, 1000 Skopje, Macedonia. that the kinetics of these cells are strongly influenced by changes in dentin permeability. The initial response of pulpal dendritic cells trigger the development of most pulpal pathosis of clinical importance. Upon antigenic challenge, these cells may not only interact locally with T-lymphocytes as antigen-presenting cells, but also communicate with nerves and the vasvascular system, which can modulate inflammatory reactions. Hence, pulpal dendritic cells appear to provide the pulpal connective tissue with potentials far beyond what was previously anticipated $(8,9)$.

Changes of the distribution of class II-expressing cells have been shown in rat incisors during tooth development, as well as in molar pulp and the responses of class II-expressing cells to experimentally induced pulpitis have also been reported $(10,11,12,13)$.

Izumi (14) showed that human dental pulp contains two kinds of class II MHC antigen-expressing cells: dendritic cells and macrophages (15). Both dendritic cells and macrophages are believed to participate in the immune defense system in the dental pulp. Class II molecule-expressing pulpal dendritic cells are of primary importance because of their critical role in pulpal immuno-surveillance. In general, dendritic cells differ from macrophages in their little or no phagocytotic activity, in contrast to the macrophages, which possess a high phagocytotic activity $(16,17)$. In intact teeth, enamel and cementum protect dentinal pulp from external stimuli transmitted through dentinal tubules. Under carious conditions, however, the pulp tissue is subject to constant exposure to antigenic stimuli. These differences in environment might affect the distribution of class II-expressing cells in dental pulp $(18,19)$. 


\section{9-253}

The purpose of this study was to elucidate the distribution of class II-expressing cells in developing, healthy and carious human teeth, to clarify, when human pulp acquires an immunologic defense potential and how this reacts to dental caries.

\section{Materials and methods}

Four partially developed unerupted teeth were operatively extracted, four erupted developing intact premolars, and four premolars with closed apices were extracted. Ten premolars with various stages of decay were obtained from patients exhibiting no clinical symptoms. Teeth were obtained from patients, who needed orthodontic therapy and were from 11 to 18 years old.

Immediately after extraction, teeth were cut longitudinally; the dental pulp was extirpated and fixed in $10 \%$ buffered paraformaldehyde, embedded in paraffine and sliced into 4-5 mm sections. The depth of each caries lesion was determined by the pigmentation on the sections.

\section{Immunostaining}

Sections were deparaffinized, hydrated and washed in phosphate-buffered saline. They were incubated in $0.3 \% \mathrm{H}_{2} \mathrm{O}_{2}$ for 30 min to block the endogenous peroxidase, and then with the primary antibodies for 1 hour. Primary antibodies were anti-HLADR monoclonal antibody (CR3/43; DAKO Co. Ltd, Denmark) and rabbit anti-CD 68 polyclonal antibody (DAKO). The binding primary antibody was visualized with the Stravigen Immunostaining kit (Biogenex Laboratories, Dublin, U.S.A.). Finally, the localization of peroxidase activity was visualized by incubation of the sections with 3'.3'-diaminobezidin (DAB) in phosphatebuffered saline for five to seven minutes and counterstained with hematoxylin. All immunostaining steps were completed at room temperature. Negative control staining was done by omitting exposure to primary antibodies and no immunoreactive product was detected. Immunostained cells were counted under a light microscope (BH2, OLYMPUS) at a magnification of $\times 200$.

\section{Results}

\section{Unerupted developing teeth}

During the stage of root formation, numerous HLA-DR-positive cells and macrophages appeared in the coronal pulp. Distribution of HLA-DR-positive cells was especially dense in and around the odontoblast layer. Only a few HLA-DR-positive cells were scattered in the dental papilla (Fig. 1).

A few CD68 positive cells were located more coronary around the blood vessels (Fig. 2).

\section{Erupted, intact teeth}

Immunoperoxidase-labeled HLA-DR-positive cells were located, for the most part just beneath the odontoblast layer. In the connective tissue of the coronal and radicular pulp, they were distributed mainly around the blood vessels (Fig. 3).

CD68 positive cells were also located coronary, mainly around the blood vessels (Fig. 4).

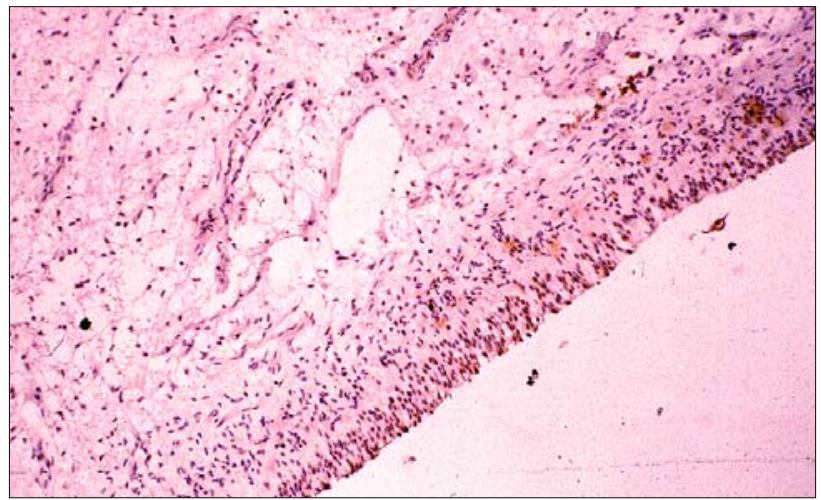

Fig. 1. Immunohistochemical localization of HLA-DR positive cells in unerupted developing teeth.

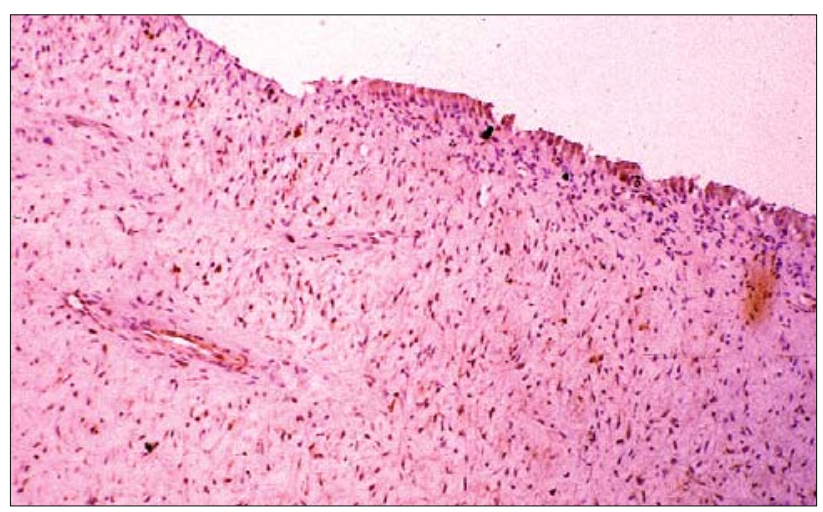

Fig. 2. Immunohistochemical localization of CD68 positive cells in unerupted developing teeth.

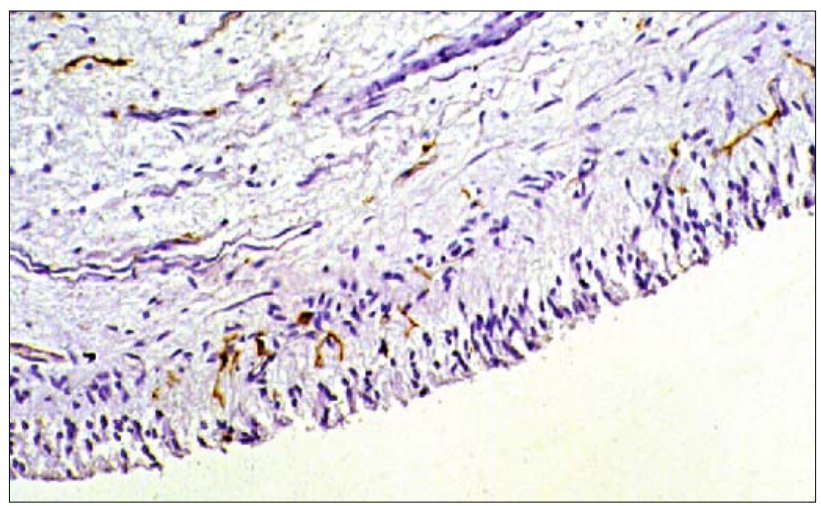

Fig. 3. Immunohistochemical localization of HLA-DR positive cells in erupted, intact teeth.

\section{Carious teeth}

In teeth, where caries lesions extended from the enamel into the dentin, an aggregation of HLA-DR-positive cells were observed in the sub-odontoblastic region. No distributive changes were noted in other areas (Fig. 5). Also, the number of the macrophages was increased in the area corresponding to the caries lesion (Fig. 6).

As the caries lesion advanced, the aggregated cells expanded along the odontoblast layer, and they advanced toward the center of the pulp (Figs 7 and 8). 


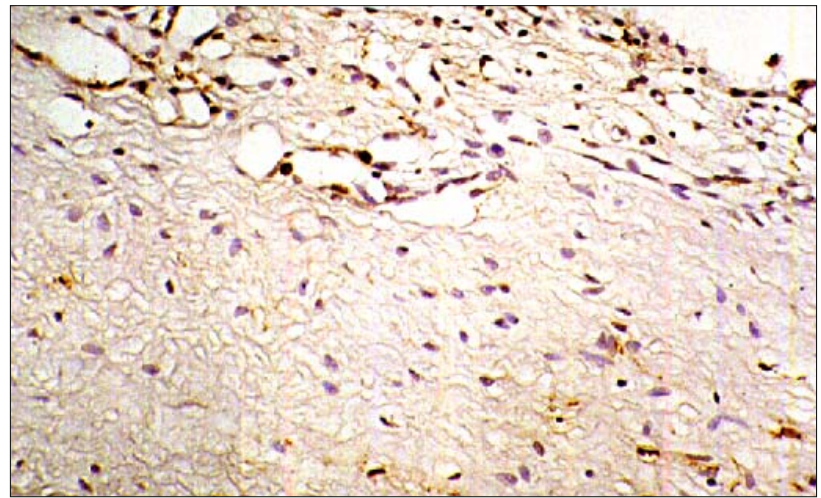

Fig. 4. Immunohistochemical localization of CD68 positive cells in erupted, intact teeth.

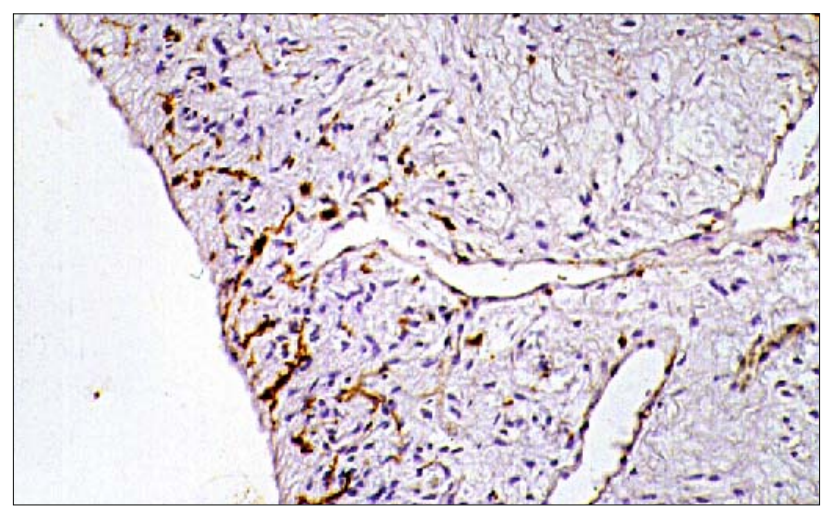

Fig. 5. Immunohistochemical localization of HLA-DR positive cells in the pulp affected by initial caries.

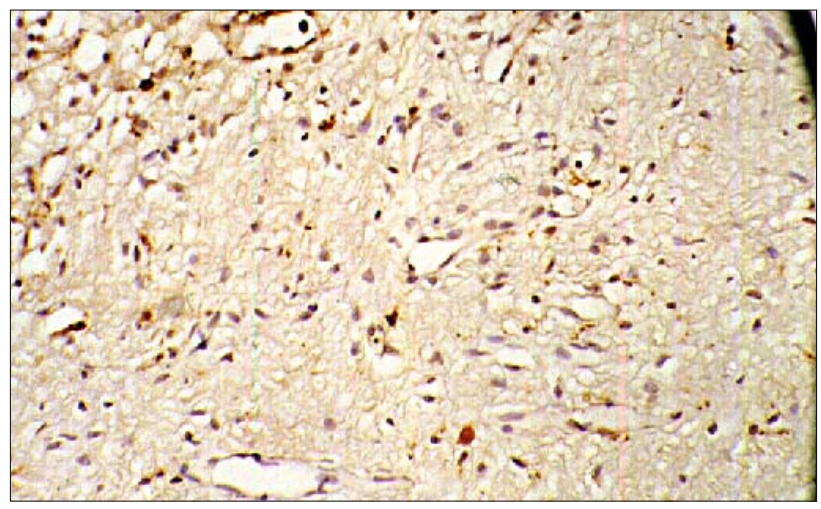

Fig. 6. Immunohistochemical localization of CD68 positive cells in the pulp affected by initial caries.

\section{Discussion}

The existence of two types of class II antigen-expressing cells-dendritic cells, which are characterized by poor phagocytic activity, and macrophages were reported in the dental pulp of both rat and human teeth $(6,20)$. Dendritic cells were localized to the periphery of the pulp, while macrophages tended to be more centrally located $(2,3,21)$.

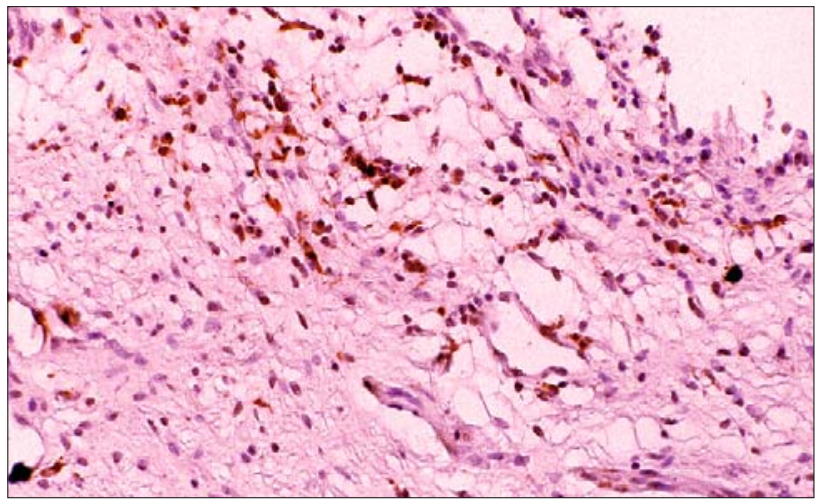

Fig. 7. Immunohistochemical localization of HLA-DR positive cells in the pulp affected by moderate caries.

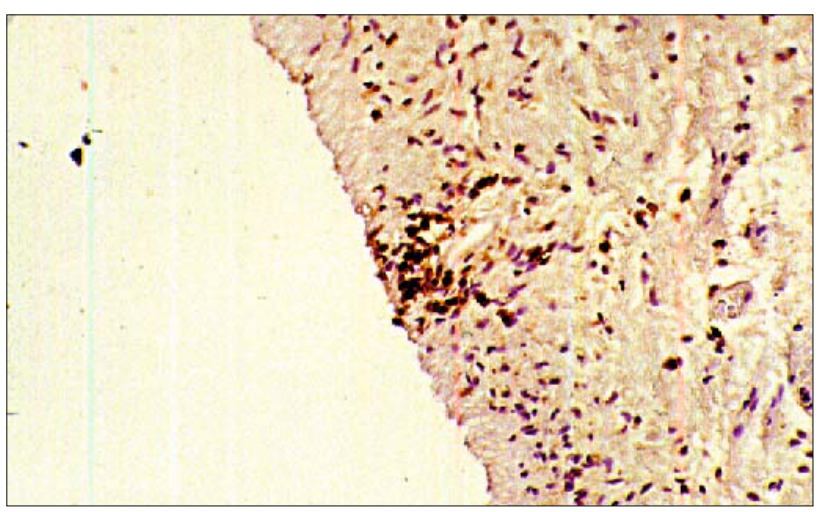

Fig. 8. Immunohistochemical localization of CD68 positive cells in the pulp affected by moderate caries.

The HLA-DR-positive cells observed throughout the odontoblast layer were dendritic cells, and their location was ideal for capturing antigens invading the dental tubules $(22,23)$. Previous studies of Jontell (10), Kosaka (11) and Yoshiba(24) on rat dental pulp showed that the majority of class II- expressing cells occurred only after eruption, suggesting that there was a post-eruptive increase due to the invasion of the bacterial antigens. On contrary to the data obtained in rats, numerous HLA-DR-positive cells were found in the pulps of unerupted human teeth concentrated within the odontoblast layer, and macrophages more centrally located around the blood vessels. Thus, the results of the present study indicated that human teeth are already equipped with an immunological defense potential before they erupt.

Antigen-presenting cells react with antigens that have reached the pulp tissue through the dentine tubules (25). Therefore, these cells in the early carious pulp may migrate into the lymph node to present antigen to T- cells. Initial antigen presentation followed by expansion of both the cell-mediated and the humoral immune reaction may occur in the dental pulp. Potential antigen-presenting cells in the pulp actually respond to the carious attack at the very early stage of dentinal caries. Most likely, these cells are functioning as sentinels of the pulpal immunological defense system to recognize externally derived carious antigens, which may be activated by the pulpal immune defense reactions (26). 
Present study is also demonstrating distributive changes in class II-expressing cells in the pulps of carious teeth. Changes were evident in teeth with early caries and the aggregation of HLA-DR-positive cells and macrophages were observed in the restricted area corresponding to caries lesion, which is suggesting that antigenic materials have already spread into the pulp tissue through dentinal tubules. Similar lymphocyte infiltration was reported during enamel caries $(27,28,29)$. The relationship between these data on carious teeth is indicated by the results of in vitro experiments, which showed that the dendritic cells in dental pulp had the capacity to co-stimulate T-lymphocytes, a relationship of importance during the early stages of pulpal immunoresponse (16).

More advanced caries induced more expanded aggregations of HLA-DR-positive cells and macrophages along the odontoblast layer and sub-odontoblastic area of the pulp. This sub-odontoblastic zone is composed of the rich network of nerve fibers, capillaries and a collagen matrix $(30,31)$. The exact role of this zone remains unknown, but the present findings suggest its importance for accommodating immuno-responsive cells. HLA-DR-positive cells were observed along the dentin pulp border corresponding to the caries lesion.

The mode of immunological reaction of the dental pulp seems to be strongly influenced by hard tissue encasement. Class-II-expressing cells are able to respond to trans dentinal antigen provocation and the kinetics of these cells are strongly influenced by changes in dentin permeability (32, 33). Upon antigenic challenge, these cells may interact locally with T-lymphocytes and induce an immunological response to mount defense and repair of the dentin pulp complex.

\section{Conclusions}

Our present findings indicate that human teeth are already equipped with an immunological defense potential prior to eruption, even before they were submitted to antigenic challenges in the mouth. In the initial stage of caries infection, an immunoresponse mediated by class-II-expressing cells is initiated in the human dental pulp.

\section{References}

1. Cox DS. Inflammation, hypersensitivity, and regulatory mediators. In: Contemporary oral microbiology and immunology. Slots J, Taubman MA (Eds). 1992, Chapter 9, pp 135-143, Mosby, Baltimore.

2. Jontell M, Gunray MN, Bergenholtz G. Immunocompetent cells in the normal dental pulp. J Dent Res 1987; 66: 1149-1153.

3. Jontell M, Bergenholtz G, Scheynius A, Ambrose W. Dendritic cells and macrophages expressing class II antigens in the normal rat incisor pulp. J Dent Res 1988; 67: 1263-1266.

4. Jontell M, Bergenholtz G. Accessory cells in the immune defense of the dental pulp. Proc Finn Dent Soc 1992; 88: 344-355.

5. Okiji T, Kawashima N, Kosaka T, Matsumoto A, Kobayashi C, Suda H. An immunohistochemical study of the distribution of imunocompetent cells, especially macrophages and Ia antigen-expressing cells of heterogenous populations, in normal rat molar pulp. J Dent Res 1992; 71 (5): 1196-1202.
6. Ohshima H, Kawahara I, Maeda T, Takano Y. The relationship between odontoblasts and immunocompetent cells during dentinogenesis in rat incisors:an immunohistochemical study using OX6-monoclonal antibody. Arch Histol Cytol 1994; 57: 435-447.

7. Steinman PM. The dendritic cell system and its role in immunogenicity. Ann Rev Immunol 1991; 9: 271-296.

8. Ebersole JL. Cells and tissues of the immune system. In: Contemporary oral microbiology and immunology. Slots J, Taubman MA (Eds), 1992, Chapter 6, pp 78-116, Mosby, Baltimore.

9. Fleming S. Immunophysiology: the Immune Response. In: Muir's Textbook of Pathology. Anderson JR (Ed. 1985, 12th edn, 6.1-6.40. Arnold, Baltimore.

10. Jontell M, Jiang WH, Bergenholtz G. Ontogeny of class II antigen expressing cells in rat incisor pulp. Scand J Dent Res 1991; 99:384-389.

11. Kosaka T, Okiji T, Kawashima N, Kobayashi C, Suda H. Changes in the distribution of various immunocompetent cells in rat molar pulp during tooth development. Jpn J Conserv Dent 1992; 35: 1474-1480.

12. Ohshima $\mathbf{H}$ et al. An immunohistochemical study of the distribution of immunocompetent cells, especially macrophages and Ia antigenexpressing cells of heterogenous populations, in normal rat molar pulp. $\mathrm{J}$ Dent Res 1992; 71: 1196-1202.

13. Bergenholtz G, Nagaoka S, Jontell M. Class II antigen expressing cells in experimentally induced pulpitis. Int Endod J 1991; 24: 8-14.

14. Izumi T, Kobayashi I, Okamura K, Matsuo K, Kiyoshima T, Ishibashi Y, Inoue H, Sakai H. An immunohistochemical study of HLA-DR and $\mathrm{a}_{1}$-antichimotrypsin-positive cells in the pulp of human non-carious and carious teeth. Arch Oral Biol 1996; 41 (7): 627-630.

15. Ohshima H, Maeda T, Takano Y. The distribution and ultrastructure of class II MHC-positive cells in human dental pulp. Cell Tissue Res 1999; 295: 151-158.

16. Jontell M, Eklog C, Dahlgren UI, Bergenholtz G. Difference in capacity between macrophages and dendritic cells from rat incisor pulp to provide accesory signals to concavalin-A-stimulated T-lymphocytes. J Dent Res 1994; 73 (5): 1056-1060.

17. Kim S, Trowbridge HO. Pulpal reaction to caries and dental procedures. In: Pathways of the pulp. Cohen S and Burns RC (Eds). 1998. Chap 15, pp 414 - 434, Mosby, Baltimore.

18. Farges JC, Alliot-Licht B, Baudouin C, Msika P, Bleicher F, Carrouel F. Odontoblast control of dental pulp inflammation triggered by cariogenic bacteria. Front Physiol 2013; 4: 326.

19. Kamal AMM, Okiji T, Kawashima N, Suda N. Defence responses of dentin/pulp complex experimentally induced caries in rat molars: An immunohistochemical study on kinetics of pulpal Ia antigen-expressing cells and macrophages. J Endod 1997; 23 (2): 115-120.

20. Ohshima H, Sato O, Kawahara I, Maeda T, Takano Y. Responses of immunocompetent cells to cavity preparation in rat molars: An immunohistochemical study using OX6-monoclonal antibody. Connect Tissue Res 1995; 32: 303-311.

21. Jontell M, Bergenholtz G, Scheynius A, Ambrose W. Dendritic cells and Macrophages expressing class II antigens in the normal rat incisor pulp. J Dent Res 1998; 67 (10): 1263-1266.

22. Banchereau J, Steinman RM. Dendritic cells and the control of immunity. Nature 1998; 392: 245-252.

23. Rescigno M, Urbano M, Valzasina B, Francolini M, Rotta G, Bonasio R, et al. Dendritic cells express tight junction proteins and 
penetrate gut epithelial monolayers to sample bacteria. Nat Immunol 2001; 2 (4): 361-367.

24. Yoshiba N, Yoshiba K, Nakamura H, Iwaku M, Ozawa H. Immunohistochemical localization of HLA-DR-positive cells in unerupted and erupted normal and carious human teeth. J Dent Res 1996; 22.75: 1585-1589.

25. Lehner T. Immunology of oral diseases. 1992. Chap. 4, pp 28-47, Blackwell Scientific Publications, Oxford.

26. Sakurai K, Okiji T, Suda H. Co-increase of nerve fibers and HLA-DRand/or factor-XIIIa-expressing dendritic cells in dentinal caries-affected regions of the human dental pulp: An immunohistochemical study. J Dent Res 1999; 78 (10): 1596-1608.

27. Izumi T, Kobayashi I, Okamura K, Sakai H. Immunohistochemical study on the immunocompetent cells of the pulp in human non-carious and carious teeth. Arch Oral Biol 1995; 40 (7): 609-614.

28. Nahn CL, Liewehr FR. Innate immune responses of the dental pulp to caries. J Endod 2007; 33 (6): 643-651.
29. Sotirovska-Ivkovska A, Ivkovski L, Bajraktarova B, Georgiev Z, Zabokova-Bilbilova E. An immunohistochemical study of antigen-presenting cells in the human dental pulp. Int Dent J 2000; (Supplement) 6: 353.

30. Goldberg M, Farges JC, Lacerda-Pinheiro S, Six N, Jegat N, Decup F, et al. Inflammatory and immunological aspects of dental pulp repair. Pharmacol Res 2008; 58 (2): 137-147.

31. Farges JC, Alliot-Licht B, Baudouin C, Msika P, Bleicher F, Carrouel $\mathbf{F}$. Odontoblast control of dental pulp inflammation triggered by cariogenic bacteria. Front Physiol 2013; 4: 326.

32. Jontell M, Okiji T, Dahlgreen U, Bergenholtz G. Immune defence mechanisms of the dental pulp. Crit Rev Oral Biol Med 1998; 9 (2): 179200.

33. Taubman MA. Immunological aspects of dental caries. In: Contemporary oral microbiology and immunology. Slots J, Taubman MA (Eds). 1992, Chapter 29, pp 533-541, Mosby, Baltimore.

Received November 24, 2017. Accepted January 11, 2018. 